\title{
Correction
}

\section{Correction: Reduction in bone relapse and improved survival with oral clodronate for adjuvant treatment of operable breast cancer [ISRCTN83688026]}

Trevor Powles ${ }^{1}$, Alexander Paterson ${ }^{2}$, Eugene McCloskey ${ }^{3}$, Phil Schein ${ }^{4}$, Bobbi Scheffler ${ }^{5}$, Alwynne Tidy ${ }^{6}$, Sue Ashley ${ }^{6}$, lan Smith ${ }^{6}$, Lars Ottestad ${ }^{7}$ and John Kanis ${ }^{3}$

${ }^{1}$ Parkside Oncology, London, UK

${ }^{2}$ Tom Baker Cancer Centre, Calgary, Alberta, Canada

3WHO Collaborating Centre for Metabolic Bone Diseases, University of Sheffield Medical School, Sheffield, UK

${ }^{4}$ Department of Clinical Pharmacology, University of Oxford, Oxford, UK

${ }^{5}$ Scheffler Group, Villanova, Pennsylvania, USA

${ }^{6}$ Royal Marsden Hospital, London, UK

${ }^{7}$ Radium Institute, Oslo, Norway

Corresponding author: Trevor Powles, hdummer@parkside-hospital.co.uk

Published: 3 May 2006

This article is online at http://breast-cancer-research.com/content/8/3/406

Breast Cancer Research 2006, 8:406 (doi:10.1186/bcr1413)

(c) 2006 BioMed Central Ltd

It has been brought to our attention that there was a typographical error in our recent article [1] published in March 2006.

In the Conclusions section the final sentence should read:

Questions such as the optimal duration of therapy and efficacy in stage I disease remain to be answered.

\section{References}

1. Powles T, Paterson A, McCloskey E, Schein P, Scheffler B, Tidy A, Ashley S, Smith I, Ottestad L, Kanis J: Reduction in bone relapse and improved survival with oral clodronate for adjuvant treatment of operable breast cancer [ISRCTN83688026]. Breast Cancer Research 2006, 8:R13. 